Multi-Channel Surface Electromyography for Simultaneous and Proportional Control of Prostheses 



\section{Multi-Channel Surface Electromyography for Simultaneous and Proportional Control of Prostheses}

\section{PhD Thesis by}

Silvia Muceli

Department of Health Science and Technology, Aalborg University, Denmark

River Publishers

Aalborg 
ISBN 978-87-93102-36-1 (e-book)

Published, sold and distributed by:

River Publishers

Niels Jernes Vej 10

9220 Aalborg Ø

Denmark

Tel.: +45369953197

www.riverpublishers.com

Copyright for this work belongs to the author, River Publishers have the sole right to distribute this work commercially.

All rights reserved (c) 2013 Silvia Muceli.

No part of this work may be reproduced, stored in a retrieval system, or transmitted in any form or by any means, electronic, mechanical, photocopying, microfilming, recording or otherwise, without prior written permission from the Publisher. 


\section{PREFACE}

This $\mathrm{PhD}$ dissertation, entitled "Multi-channel surface electromyography for simultaneous and proportional control of prostheses", is based on four original papers that were published in international peer-reviewed journals. The studies will be referred in the Thesis by Roman numbers I-IV.

Study I: Muceli S and Farina D.

Simultaneous and proportional estimation of hand kinematics from EMG during mirrored movements at multiple degrees-of-freedom. IEEE Trans Neural Syst Rehabil Eng 20: 3: 371-378, 2012.

Study II: Jiang N, Vest-Nielsen JL, Muceli S and Farina D.

EMG-based simultaneous and proportional estimation of wrist/hand kinematics in uni-lateral trans-radial amputees. J Neuroeng Rehabil 9: 1: 1-11, 2012.

Study III: Jiang N, Muceli S, Graimann B and Farina D.

Effect of arm position on the prediction of kinematics from EMG in amputees. Med Biol Eng Comput 1-9, 2012.

Study IV: Muceli S, Jiang N, and Farina D.

Extracting Signals Robust to Electrode Number and Shift for Online Simultaneous and Proportional Myoelectric Control by Factorization Algorithms. IEEE Trans Neural Syst Rehabil Eng. In press. 


\section{ABSTRACT}

The loss of an upper limb affects task functionality, grasping patterns and dexterity abilities.

Intensive research has been devoted to restore multiple functions. However, most commercial hand prostheses are simply grippers. In the best case scenario, wrist rotation is also provided, but the two functions can only be activated sequentially. Upper limb prosthesis users are urgently requesting for additional wrist functions, more intuitive control and simultaneous articulation of multiple functions.

In research settings, pattern recognition-based myoelectric controllers achieve impressive accuracy in classifying tasks involving several types of contractions. However, results are often obtained from intact limb subjects in very controlled laboratory conditions. Classification accuracy degrades in real life scenario, due for example to use of the prosthesis in multiple positions or to electrode shift.

The aims of this thesis were to propose myoelectric control systems for continuous, simultaneous and proportional control of the wrist/hand functions during dynamic movements (Studies I-IV) and to test the robustness of such systems with respect to the number of EMG channels used to infer the user intents (Studies I and IV), to variations in limb position (Study III), to electrode shift (Study IV), when applied to amputees with respect to normally-limbed subjects (Studies II-III).

Study I proposes a method based on artificial neural networks to estimate kinematics of the complex wrist/hand from multi-channel EMG electrodes during movements in free space. The system was tested in able-bodied subjects to provide a benchmark for successive validation in amputees. To simulate a training strategy applicable with unilateral amputees, subjects performed mirrored bilateral movements while kinematic and EMG data were acquired from an arm each. The system proposed in Study I was validated in Study II in transradial amputees with amputation proximal or distal to the elbow. Performances were different depending on the stump length. Kinematics estimation was accurate in case of individual with distal 
amputation. Study III showed that the system is also robust to variations in limb position if accounted during training. Therefore, the system proposed in Study I and validated in Studies II and III can be used for providing proportional and simultaneous control of multiple functions in unilateral amputees. However, it cannot be applied to bilateral amputees because of the need of kinematic data. This limitation was circumvented in Study IV by using a control system based on factorization of the EMG signals. The system does not require kinematic data and was proven to be robust to the number of EMG channels and to electrode shift. 


\section{ABSTRAKT}

Personer, der har mistet en af de øvre ekstremiteter, oplever en ændring af funktionsdygtigheden, samt med hvilke greb og grad af finmotorik disse funktioner kan udføres. Megen forskning arbejder i retning af at genoprette denne funktionsdygtighed. På trods af dette er hovedparten af kommercielle håndproteser såkaldte simple gribere. I bedste fald er rotation omkring håndleddet også mulig, men disse to funktioner er kun

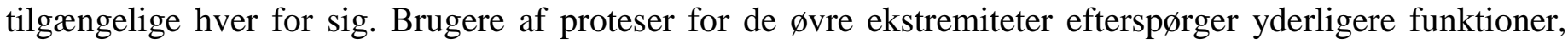
højere grad af intuitive kontrol, samt muligheden for at udføre flere funktioner samtidig.

Indenfor forskningsmiljøet har myoelektrisk kontrol baseret mønstergenkendelse opnået høj grad af præcision i at klassificere funktioner, der involverer flere forskellige typer kontraktioner. Disse resultater er dog oftest opnået på ikke-amptuterede personer i meget vel-kontrollerede omgivelser i et laboratorium. I mere realistiske omgivelser vil en del af præcisionen af klassifikationerne gå tabt pga. f.eks. brugen af protesen i forskelle kropspositioner eller mindre ændringer i elektrodernes placering.

Målene med denne tese var udvikle myoelektriske kontrolsystemer til kontinuerlig, simultan og proportionel kontrol af håndledets/håndens funktioner under dynamiske bevægelser (studierne I-IV) og at undersøge robustheden af disse systemer $\mathrm{i}$ forhold til antallet af EMG kanaler der anvendes til at udlede brugerens intention (studierne I og IV), variationer i lemmernes position (Studie III), ændringer i elektrodernes placering (Studie IV), samt i forbindelse med anvendelse af systemet på amputerede fremfor ikkeamputerede personer (studierne II-III).

I studie I præsenteres en metode baseret på artificial neural networks til at estimere håndledets/håndens kinematik ud fra data fra multi-kanal EMG elektroder under frie bevægelser. Systemet blev testet på ikkeamputerede for at have en reference til brug af validering af systemet på amputerede. For at simulere en træningsstrategi der kunne overføres til amputerede personer, udførte testpersonerne symetriske, bilaterale 
bevægelser, mens kinematikken og EMG-signalerne blev optaget fra begge lemmer. Systemet (præsenteret i studie I) blev valideret i Studie II på transradiale amputerede, med amputationen proksimalt eller distalt i forhold til albuen. Systemets effektivitet afhang af amputationens placering. Studie III demonsterede at systemet også er robust i forhold amputationens placering, såfremt der tages højde for det i forbindelse med træningen af systemet. Således blev det valideret at systemet der blev præsenteret i Studie I og valideret i Studie II og III kan anvendes til give proportionel og simultan control af flere funktioner for unilaterale amputerede. Systemet kan dog ikke implementeres for bilaterale amputerede pga. behovet for kinematisk data. Denne begrænsning blev omgået i Studie IV ved brug af et kontrol system baseret på faktorisering af EMG signalet. Systemet kræver dermed ikke kinematisk data og blev påvist at være robust i forhold til antallet af EMG kanaler samt ændringer i elektrodernes placering. 


\section{ACKNOWLEDGMENTS}

The work reported in this thesis was carried out at the Center for Sensory-Motor Interaction (SMI), Aalborg University, Denmark, in close cooperation with the Department of Neurorehabilitation Engineering (NRE), Georg-August University of Göttingen, Germany, which I visited during the last year of the Ph.D. study. Financial support was provided by the Regione Autonoma della Sardegna (Italy), which I gratefully acknowledge.

I wish to express my sincere gratitude to my supervisor Prof. Dario Farina for his constant encouragement and support through the project. I am very grateful to him for introducing me to the biomedical field and giving me the opportunity to participate in many research projects. His supervision provided an invaluable contributing to my scientific development.

I would like to thank all coauthors of the studies presented in this thesis, especially Dr. Ning Jiang for his extensive contribution to the studies included in this thesis and for the fruitful collaboration. Johnny LG Vest-Nielsen is also acknowledged for his collaboration, especially during the experimental work.

I am grateful to all my colleagues and friends at SMI and NRE. In particular, I would like to thank Francesco Negro who encouraged me to join SMI and, together with Antonietta Stango, helped me whenever needed. I had the pleasure to share my Danish experience with Carolina Vila-Chã who arrived in Aalborg the same week I did and left Aalborg at the same time as me. She was a formidable colleague, neighbor and friend. A big thanks to Saba Gervasio for the exuberance she brought to the office and for her friendship. Thanks to Silvia Lo Vecchio for the help in the laboratory. Thanks to the office mates Liliana Parades, Vahid Shalchyan and Marko Markovic for the positive environment at work. I am grateful to Strahinja Dosen who was always ready to help. Thanks to Jakob Lund Dideriksen for translating the abstract of this thesis. I want to thank my friends from the “Am Vogelsang building”, especially Jovana Kojovic, Leonardo Gizzi and Claudia 
Marvisi,for the nice time spent together. Claudia is also acknowledged for providing graphical advices. Thanks to the "Cappuccino team" in Aalborg and the "Brunch team" in Göttingen for the nice weekends. Thanks to all these people, my stay in Denmark and Germany was an incredible professional and life experience.

Thanks to the SMI secretariat for providing all necessary assistance and for their kindness.

I finally wish to thank deeply my family, especially my mother, my father, Carlo and Giuliana, to whom my efforts, including this thesis, are always dedicated. To live far apart has not been easy but they accepted my will to try an experience abroad and they provided constant support and understanding. "Grazie! Questa tesi è dedicata a voi". 


\section{TABLE OF CONTENTS}

PREFACE

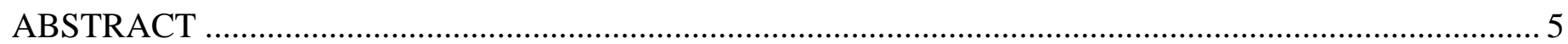

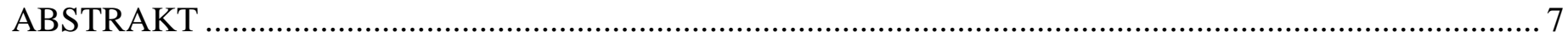

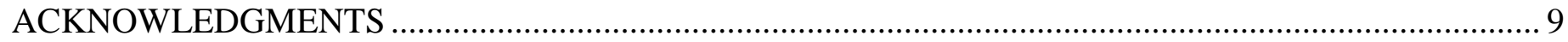

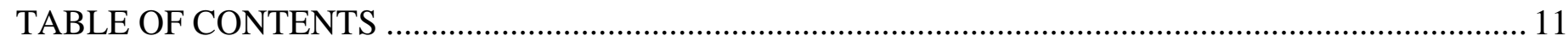

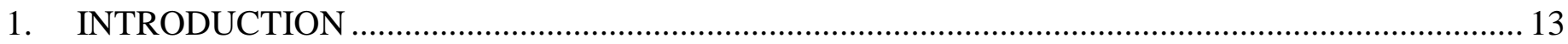

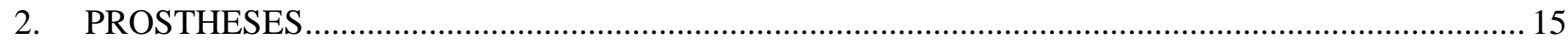

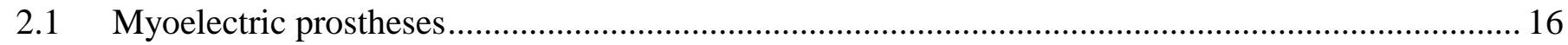

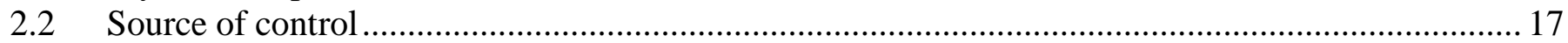

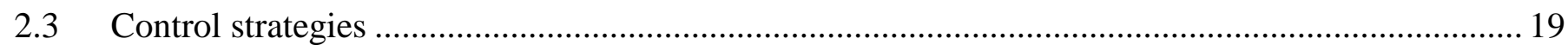

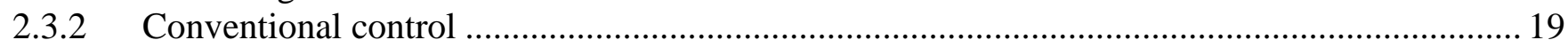

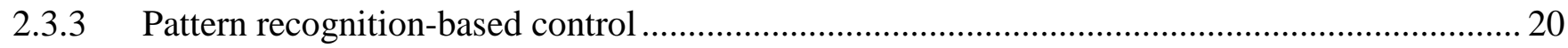

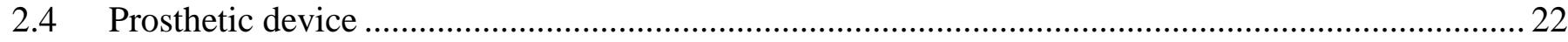

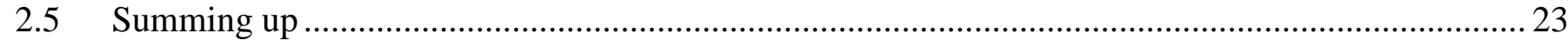

3. GAP BETWEEN RESEARCH FINDINGS AND CLINICAL IMPLEMENTATION ............................ 25

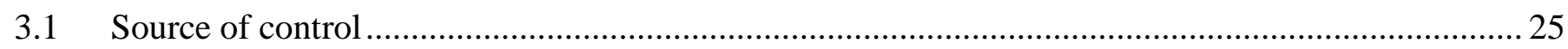

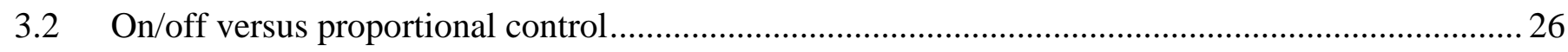

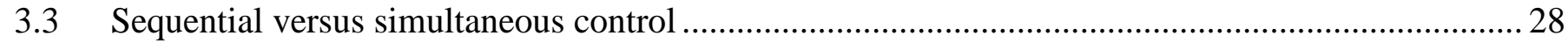

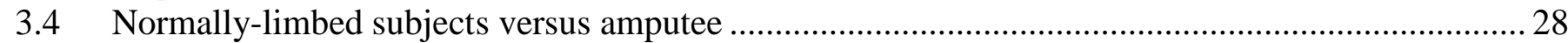

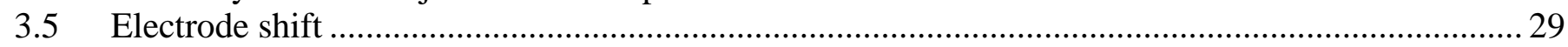

3.6 Training procedure

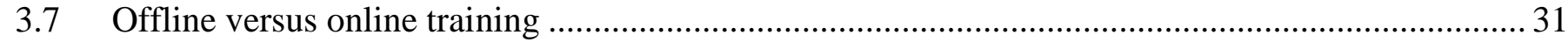

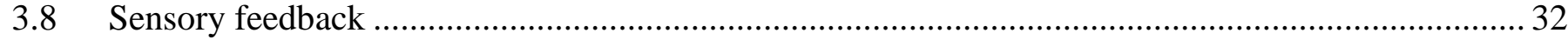

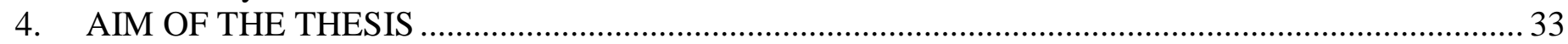

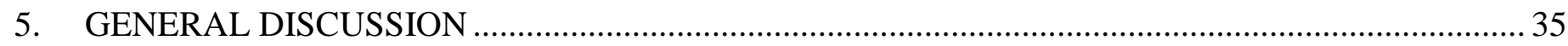

5.1 Unresolved issues in simultaneous and proportional control of multiple DOFs .................................. 35

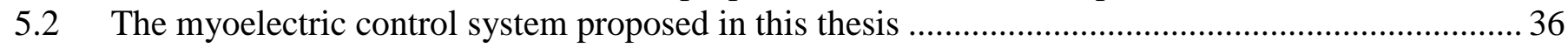

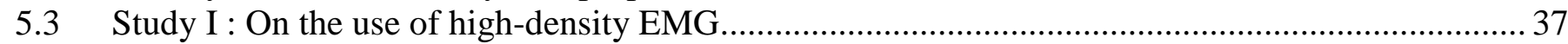

5.4 Study II : Validation of the proposed myoelectric control strategy in amputees................................. 38

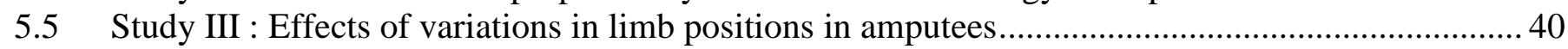

5.6 Study IV: Robustness to electrode shift of a control strategy for bilateral amputees .......................... 41

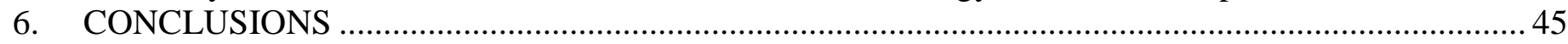

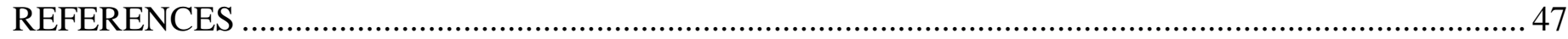




\section{INTRODUCTION}

When we imagine or perform a movement, upper motor neuron in the primary motor cortex fire. Their axons descend all the way into the spinal cord, where they make the final relay of information to the alpha motor neurons. Their axons reach skeletal muscles via peripheral nerves. The activation of muscles results in force production, and ultimately in movement or stabilization of skeletal joints. Motor impairment may result from damage of the pathway from the brain to the muscles, e.g., following spinal cord injury. In this case, the impulses from the upper motor neurons cannot reach the target muscle. On the other hand, in case of amputation, the pathways remain intact. Therefore, the efferent signal still reaches the muscles above the level of the amputation, but the movement cannot be executed because the limb is missing (Popović and Sinkjaer 2000).

Regardless of the affected limb, amputation is always a traumatic experience that reduces the quality of life, the well-being and the working capacity of patients. Lower limb loss, even unilateral, compromises balance and ambulation. The loss of an upper limb affects task functionality, grasping patterns and dexterity abilities. In case of the dominant side, the amputee has to relearn how to do even the simplest tasks. Moreover, the loss of the hand restricts the individual capacity to perceive the surrounding world because the sensibility of the hand is extremely well developed, as demonstrated by the large territory occupied in the somatosensory cortex (Penfield and Boldrey 1937). Although research to restore motor function in upper limb amputees has flourished in the last 50 years, most commercial hand prostheses are simply grippers. Therefore, the dissatisfaction rate of patients is so high that they often decide to abandon the prosthesis (Wright et al 1995). All these limitations motivate the development of novel techniques to restore sensory-motor functions and thus to improve the quality of life of amputees. This progress is further motivated by the fact that most of the upper limb amputations are of traumatic origin, and thus occur in younger persons who are healthy otherwise (Dillingham et al 1998). 
This dissertation has the aim to provide a step forward toward an intuitive control of upper limb prosthetic devices. 


\section{PROSTHESES}

Missing or lost parts of the body can be replaced by artificial extremities named prostheses (Graimann and Dietl 2013). Lower and upper limb prostheses are different in terms of functional demands. An artificial leg is required to enable a person to stand and perform cyclic movements, e.g., walking and running. A prosthetic arm should perform goal directed movements. Perhaps because the second task is more challenging, artificial arms are only a bland surrogate of the limb they are meant to replace, whereas commercial lower limb prostheses are quite effective in replacing the missing functions (McKeever 1944; Raichle et al 2008). This thesis will focus on control of upper limb prostheses; therefore, in the remaining of the thesis, when we will use the term prostheses, the reference to upper limb is implicit.

The number of joints constituting a prosthesis is determined by the level of amputation. Amputation may occur below the wrist (transcarpal), at the wrist (wrist disarticulation), below the elbow (transradial), at the elbow (elbow disarticulation), above the elbow (transhumeral), at the shoulder (shoulder disarticulation), above the shoulder (forequarter). The higher the amputation level, the higher the amputee demands in terms of prosthesis functionality. Depending on the amputation level, a prosthesis will include a hand, a wrist unit, an elbow system, a shoulder joint.

Prostheses follow into two categories: passive (or cosmetic) and active (or functional). Passive prostheses are used purely for aesthetic reasons, but they do not provide any function apart from support during bimanual tasks. Active prostheses instead are used with the aim to restore the missing functions. Functional prostheses can be body-powered or electrically powered. Body-powered prostheses are controlled by gross movements of the shoulder, upper arm or chest. These movements are captured by a harness and a cable system connected to a hook or a prosthetic hand. An important characteristic of body-powered prostheses is that they provide the user with extended proprioception (Simpson 1974), meaning that the amputee becomes aware of 
the position or the state of the terminal device because of the pressure exerted by the harness on the shoulder (Doubler and Childress 1984). On the other hand, the harness is also uncomfortable, due to the shoulder loading, and anti-cosmetic.

Electrically powered prostheses use electrical power to drive actuators. Command signals may be generated by switches or by voluntary contraction of muscles (myoelectric control) that operate the electric motors. Electrically powered prostheses offer superior grasping force and speed than body-powered prostheses and

are less uncomfortable, but they do not provide any somatosensory feedback. Two types of control can also be combined in a hybrid prosthesis. In case of transhumeral amputation, for example, a myoelectric hand can be combined with a body-powered elbow.

The aim of this thesis is to provide advancements in myoelectric control strategies for the complex wristhand. Therefore, the rest of the chapter is dedicated to the description of the components of a myoelectric control system.

\subsection{Myoelectric prostheses}

A myoelectric prosthesis is an electrically powered prosthesis controlled by means of the electromyogram (EMG) detected from remnant muscle tissue in case of amputation or available muscles in case of congenital limb deficiency (Scott and Parker 1988). Apart from the terminal device itself, a myoelectric control system includes also an EMG detection system and a translation algorithm that converts the EMG (or a feature vector that contains the information extracted from the EMG) into a control signal to the prosthetic device. Figure 1 shows a schematic representation of the working principle of myoelectric prostheses. The next three sections are dedicated to providing more information on the three modules constituting a myoelectric system. 


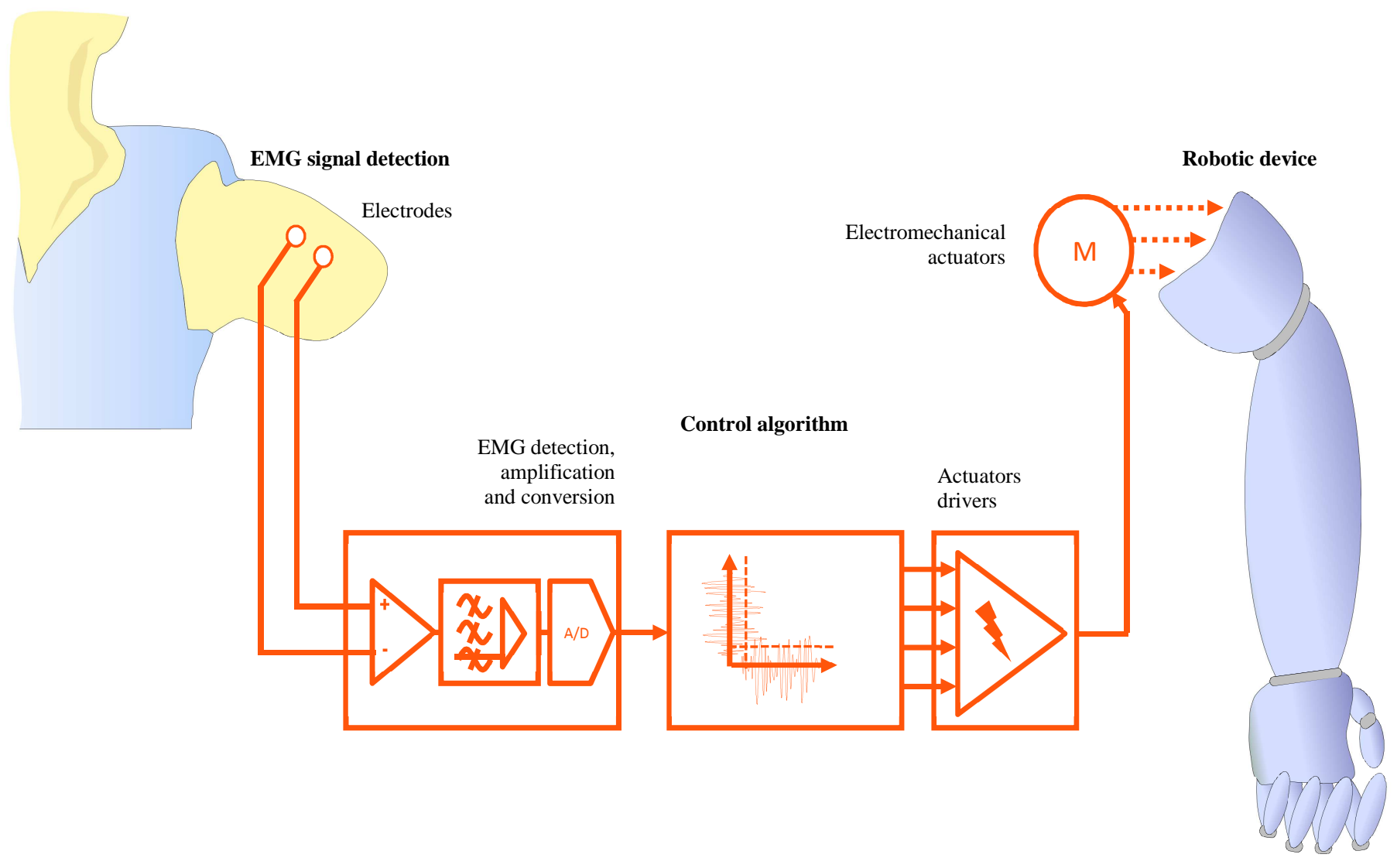

Fig. 1 Schematic representation of a myoelectric control system. The activity of residual muscles id detected through electrodes on the skin. The control algorithm actuates the prosthesis according to the control signal received from the EMG detection system. Modified from Englehart et al (2001).

\subsection{Source of control}

The classic source of control in myoelectric systems is the surface EMG (Schultz and Kuiken 2011). The surface EMG is the signal detected on the skin overlying a muscle and generated by the sum of the action potentials of the motor units active in the muscle portion underneath the detection area of the recording electrodes (Farina et al 2004). The two most important factors determining the amplitude of the surface EMG signal are the recruitment of the motor units and their firing frequency, which are also the determinants of the force output of the involved muscle (Fuglevand et al 1993). Since the variance of the surface EMG signal is related to the firing rate (Parker et al 2005), it represents an important information parameter for myoelectric 
control. The variance is typically estimated using the mean absolute value (MAV) of the signal (ZardoshtiKermani et al 1995).

Depending on the myoelectric control strategies, surface EMG is recorded from one, two or multiple channels. The reason of the widespread use of surface EMG as source of prosthesis control is the possibility of noninvasive detection. The main disadvantage associated with the use of surface EMG electrodes is that the recorded signals are easily contaminated by crosstalk because of the human connective tissue and skin layers interposed between one muscle and the electrode over it (Farina et al 2004). Crosstalk limits the number of independent control sites available as sources of control (Kuiken et al 2003).

Implantable myoelectric sensors (IMESs) for intramuscular EMG recording have been developed by Weir et al (2009) with the purpose of obtaining crosstalk free signals and consequently more independent control sources than the ones obtainable with surface electrodes. Kamavuako et al (2009) showed that features extracted from the intramuscular EMG correlate with grasping forces and can therefore be used for proportional control. Multi-channel intramuscular EMG electrodes are also under development (Farina et al 2008) with the aim to detect activity of motor units and exploit their firing rate to modulate the force exerted by the prosthesis (proportional control) (Yoshida et al 2010). Although promising, the application of intramuscular EMG for myoelectric control is still incipient and the industrial state-of-the-art still uses surface EMG to interface the stump muscles to the prosthesis.

The use of EMG may become critical in case of high-level amputees because the residual muscle tissue is reduced and the functions to be restored are numerous (myoelectric control paradox) (Parker at al 2006). In this case, it may still be possible to interface the prosthesis to the residual nerves rather than to the muscles because, as stated in Chapter I, the pathway between the brain and the muscles remains functional following amputation (Dhillon et al 2004). The inherent problem with the electroneurogram is the low amplitude and contamination from the EMG of nearby muscles (Micera et al 2010). 
An elegant technique for increasing the number of control sites in high-level amputees is the targeted muscle reinnervation (TMR) (Kuiken et al 2004) by means of which residual nerves from an amputated limb are rerouted to remaining muscles which are no longer functional due to the limb loss. The reinnervated muscles act as biological amplifier of the nerve signals providing sites accessible with surface EMG electrodes (Zhou et al 2007).

\subsection{Control strategies}

In order for the prosthesis to function, EMG signals need to be converted into commands to the prosthesis. In this respect, there is a sharp separation between the control systems embedded in commercial prostheses and the ones proposed in the literature. Next two sections will elucidate the working principles of the two control strategies.

\subsubsection{Conventional control}

The principles of the conventional control strategy, introduced in 1960', held steady until nowadays. It includes two schemes known as 2-site/2-function (or dual site) and 1-site/2-function (or single site). The dual site control paradigm was implemented in the first commercial myoelectric arm (Kobrinski et al 1960). The system controlled two functions (opening and closing) based on the contraction of antagonistic extensor and flexor muscles. This operation modality is still employed in modern prosthesis and its strong points are simplicity and robustness. The control principle is basic: the signal from a target muscle is recorded with a bipolar electrode, rectified, low-pass filtered and, when it exceeds a preset threshold, the corresponding function is activated either in an on/off manner or in a proportional way (see Fig. 1). In case of on/off control, a function is either activated (at constant speed) or not. In case of proportional control, the EMG amplitude modulates the speed of the prosthetic joint movement (Fougner et al 2012). The drawback of the dual site 
control strategy lies in the fact that two muscles are required for each DOF of the prosthesis; therefore, the total number of functions that can be provided is limited, especially in case of proximal amputation.

To circumvent this limitation, Dorcas and Scott (1966) introduced the three-state myoelectric controller in which each myoelectric channel controls both functions of the same DOF depending on the activation level (single site control scheme). For example, a weak contraction opens the prosthetic hand, whereas a strong contraction closes it. Theoretically, the above strategy can be used to provide more than two functions by multi-level coding of the amplitude of the EMG channel, but the system becomes more prone to error by the prosthesis user as the number of levels increases. Moreover, the single site system is relatively less intuitive than the dual site one that is based on a direct association between one muscle and one prosthetic command.

Therefore, whenever it is possible, the dual site strategy is preferred to the single site one. Let's consider for example the case where 2 devices (wrist and hand) need to be controlled. Theoretically, it may be possible to detect EMG from flexor and extensor muscles and to actuate each joint by modulating the amplitude of one muscle. On the other hand, it is common practice to control both devices with the dual site approach and to switch from one joint to the other by co-contracting the two muscles. This sequential operation modality constitutes the main disadvantage of the conventional control approach, together with the limitation on the number of functions that can be provided and that normally does not exceed two. Moreover, the user is often trained to generate muscle contractions that do not have any relation with the normal arm function that the prosthetic device is replacing, which makes the control strategy unnatural. Despite these limitations, this approach is implemented in most commercial devices because of its robustness.

\subsubsection{Pattern recognition-based control}

The conventional control strategy can provide as many functions as many independent sources of control are available. This requirement is very restrictive for high-level amputees for whom numerous functions would 
need to be restored. However, the presence of crosstalk in the surface EMG is not necessarily a limiting factor. Indeed, crosstalk provides plenty of spatio-temporal information across channels that can be explored to infer the user intentions. In fact, amputees are able to produce different movements of their phantom limb, associated with activity patterns of the stump muscles distinct and reproducible over time (Reilly et al 2006). This property provided the rationale for the introduction of pattern recognition in myoelectric control with the aim of making more functions available (Wirta et al 1978).

Research on pattern recognition-based myoelectric control has evolved mainly in two directions: 1) to increase the number of EMG detection sites; 2) to increase the information extracted from each EMG channel. On the first line, Englehart et al (2001) showed that four channels of EMG signals improved the classification accuracy compared to two channels in a 6-motion class problem. Hargrove et al (2007a) demonstrated that only three channels are necessary to provide an excellent accuracy in classifying 6 motions, if placed in the appropriate positions. Huang et al (2008) found out in TMR patients that using only 12 selected bipolar electrodes rather than a high-density configuration of 128 electrodes, the accuracy for classifying 16 movement intents decreased of $<2 \%$. Conclusions on the number of necessary electrodes is obviously dependent on the number of motion classes, the features and the classifier adopted, the electrode configuration (targeted versus un-targeted).

The second research direction has been deeply explored (Zecca et al 2002). In an attempt to increase the information extracted from the surface EMG, investigators have proposed a variety of feature sets both in the time domain [amplitude of the EMG (Ajiboye and Weir 2005; Momen et al 2007; Shenoy et al 2008), zero crossing (Saridis and Gootee 1982; Hudgins et al 1993), AR model (Graupe and Claine 1975; Micera et al 2000); cepstral coefficients (Park and Lee 1998)] and in the time-frequency domain [short-time Fourier transform (Englehart et al 1999), wavelet transform (Lucas et al 2008), wavelet packet transform (Wang et al 2006; Chu et al 2007)]. In addition, several classification methods (artificial neural networks, ANNs, (Kelly 
et al 1990; Hudgins et al 1993), linear discriminant analysis classifiers (Englehart and Hudgins 2003; Sensinger, et al 2009), genetic algorithms (Farry et al 1997), fuzzy logic classifiers (Chan et al 2000; Ajiboye and Weir 2005), support vector machines (Shenoy et al 2008; Lucas et al 2008)) have been employed to discriminate amongst desired classes of limb activation. However, the choice of the classifier has only marginal influence on the classification accuracy with respect to that of the features (Hargrove et al 2007a). It has been proved that, irrespective of the used classifier, it may be possible to classify 7 movements in amputees with accuracy greater than $80 \%$ and 11 movements in normally-limbed subjects with more than 85\% accuracy (Scheme at al 2011). Although it would seem from the academic research that the pattern recognition approach is a viable solution to provide multiple functions, there is currently no commercial prosthesis that relies on it (Jiang et al 2012).

\subsection{Prosthetic device}

While myoelectric strategies are remained almost unchanged since their introduction in the prosthetic field (1960's), the robotic components of a myoelectric system have undergone a remarkable evolution in the march of time. The first myoelectric prosthesis was developed in 1948 (Reiter et al 1948), but it could not be used clinically because technology was not advanced enough. With the advent of the transistor, the first clinical myoelectric prosthesis (the Russian hand) appeared in 1960 (Kobrinski et al 1960). The two above devices offered one DOF (open/close) in on/off mode. Proportional control was introduced in 1965 (Bottmley 1965). In the same period, the first multifunction myoelectric hands started to appear: the Belgrade Hand (Rakic 1969), which provided multiple types of grasp, and the SVEN-Hand (Herberts and Petersen 1970), which had two types of grasp, wrist flexion/extension and rotation.

Interest in myoelectric control expanded in 1960's thanks to the contribution of Ottobock and Viennatone, which provided new hands, hooks, wrist rotators and elbows. The myoelectric system and the hand 
mechanisms that Ottobock developed for both companies remained essentially the same during the course of the years, as well as the basic design (Childress 1985).

Despite the fact that prostheses endowed with various functions came into sight already in 1960's, the most worldwide implanted prosthetic hand is the Ottobock SensorHand ${ }^{\mathrm{TM}}$ (http://www.ottobock.com) whose only offered function is a tripod grasp. This prosthesis requires strong forces to ensure stable grasping because digits are rigid and, therefore, compliance with the grasped object is low. All myoelectric hands commercially available until few years ago could not provide more than one or at most two DOFs (Carrozza et al 2006). Multifingered prosthetic hands recently entered the market, e.g., the Touch Bionics i-LIMB ${ }^{\mathrm{TM}}$ (http://www.touchbionics.com) and the RSL Steeper BeBionic ${ }^{\mathrm{TM}}$ (http://rslsteeper.com). In the last two mentioned hands, fingers move independently and curl to fit around the object to grasp. Some more dexterous robotic hands are also object of research [e.g., the DLR hand (Butterfaß et al 2001), the MANUS hand (Pons et al 2004), the CyberHand (Carrozza et al 2006), and the SmartHand (Cipriani et al 2011)], but not clinically available yet, mainly because of problems in providing a robust control. An example of a commercial prosthesis and a research prosthesis is shown in Fig. 2.

\subsection{Summing up}

Myoelectric control systems incrementally improved in the course of the time (Parker et al 2006). Intense research has been devoted to provide multifunction control. Research has evolved in two directions: the production of active prosthetic devices and the development of control strategies. Nevertheless, these advances did not proceed at the same speed. Advances in mechatronics have yielded prosthetic hands capable to mimic the functions that the human counterpart can provide, but currently employed control strategies are inadequate to actuate all functions offered by the prosthetics technology available nowadays. Next chapter examines the reasons of this disparity. 
A

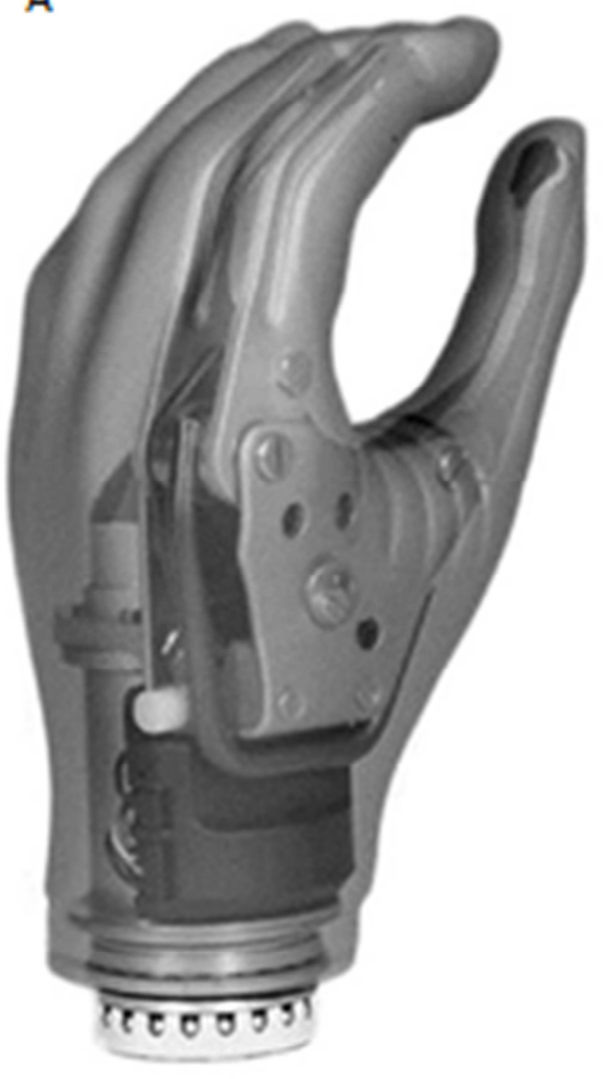

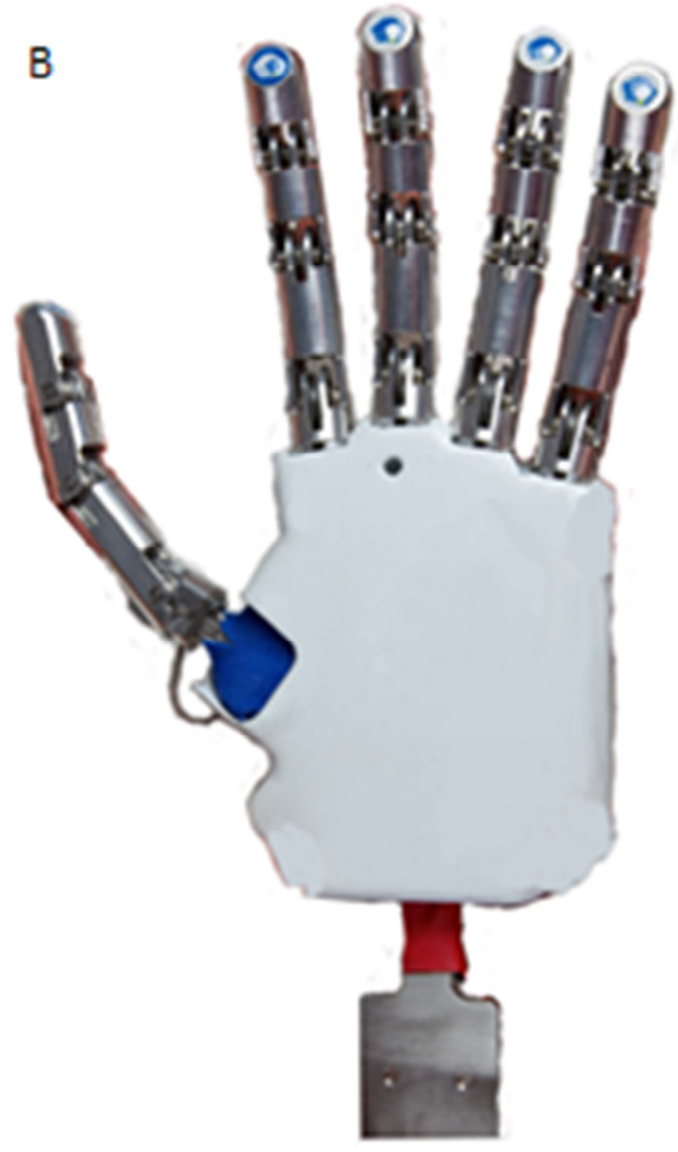

Fig. 2 (A) Otto Bock SensorHand ${ }^{\mathrm{TM}}$ Speed (Graimann and Dietl 2013). (B) The SmartHand (Cipriani et al 2011) Courtesy from Dr. Cipriani. 


\section{GAP BETWEEN RESEARCH FINDINGS AND CLINICAL IMPLEMENTATION}

The complex wrist/hand in humans includes 27 bones actuated by more than 30 muscles (intrinsic and extrinsic, some of which located in the forearm) to provide more than 19 DOFs (Graimann and Dietl 2013). To design a prosthetic system able to restore such complex system is clearly very challenging. However, commercially available myoelectric systems are not even close to reproduce the dexterity of the human counterpart. The result is that some amputees prefer cosmetic prosthesis to the active ones (Popović and Sinkjaer 2000; Biddiss and Chau 2007), and at least half of those who use active prostheses do not do it regularly (Silcox et al 1993, Carrozza et al 2006). This can be mainly attributed to low functionality and controllability along with the absence of sensory feedback (Carrozza et al. 2002). According to a survey by Atkins et al (1996), upper limb prosthesis users are explicitly demanding for more wrist functions, more intuitive control and simultaneous activation of different joints. This thesis is meant to provide a contribution in that direction, specifically on the control of prosthesis for transradial amputees.

This chapter critically reviews various aspects of the industrial and academic state-of-the-art in myoelectric control systems. The same aspects will be recalled in Chapter 5 to highlight the contributions provided by this thesis with respect to each of them.

\subsection{Source of control}

As mentioned above, a drawback of the available prosthetic systems consists in the limited functionality. High-level amputees have few sites available as sources of control, which makes more challenging the design of a prosthesis that substitutes all missing functions (Parker at al 2006). However, in case of transradial amputees, most of the muscles controlling the missing part of the limb are retained. In fact, the hand is 
mainly controlled by muscles located in the forearm. The intrinsic muscles of the hand are involved only in fine finger movements (Gilroy et al 2008). Muscles responsible for wrist movements are also located in the distal portion of the forearm (with the only exception of the pronator quadratus) and thus maintained following transradial amputation. Therefore, theoretically it should be possible to infer the movement intentions of the amputee to a large extent. Some complications come from the forearm anatomy. The forearm muscles are organized in a deep and a superficial layer. Traditionally used bipolar surface electrodes only allow the detection of the activity of superficial muscles, which are involved in hand open/close, wrist flexion/extension, and radial/ulnar deviation. Muscles responsible for wrist rotation are more difficult to access. The pronator teres is partly covered by the bicipital aponeurosis and the supinator muscle is deep (Gilroy et al 2008). This is why in commercial prostheses, rotation is controlled from forearm flexor/extensors. This makes the control not intuitive to users, as the required muscles contractions are different from the normal arm functions that the prosthesis has to replace. Although deep muscles could be reached with intramuscular electrodes, the technology is not mature yet and a non-invasive solution is preferable whenever applicable. However, even if deep muscles are not easily accessible by surface electrodes, what is relevant for control purposes is that different muscle activation patterns are associated to different functions. In this perspective, a detection configuration with several channels may reveal patterns that are unique of a specific movement. Therefore, in Study I, we investigated the use of high-density EMG electrode grids (Merletti et al 2009) for exploiting the spatial information across the muscles to improve myoelectric control. High-density grids were also used in Study IV. Figure 3 shows the electrode grids used in the two studies.

\subsection{On/off versus proportional control}

The conventional control, in its original form, provides an on/off activation of a predefined set of motions. Proportional control (with velocity proportional to the contraction intensity) is now provided by all 


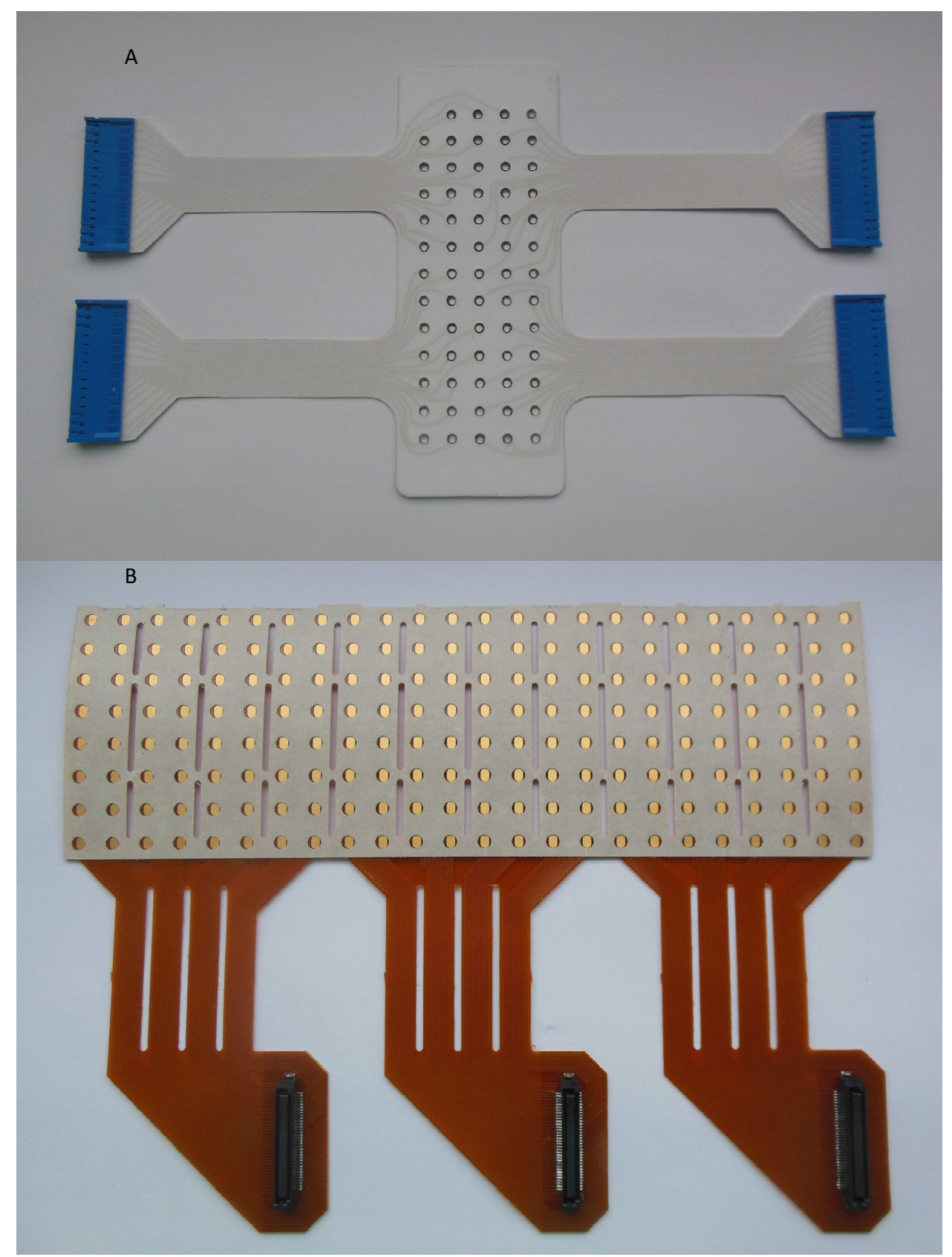

Fig. 3 High-density EMG electrode grids used in Study I (A) and Study IV (B) (http://www.otbioelettronica.it/).

commercial myoelectric prostheses (Fougner et al 2012). However, this control modality has been successfully implemented only in prostheses with limited number of functions. Implementation of proportional control in a pattern recognition system (which is the means acclaimed in the literature to provide control of multiple functions) would make the training procedure longer and more complicated and the classifier more prone to error. Conversely, natural limb movements are continuous. Therefore, the absence of proportional control causes dissatisfaction in the user. More recent research focused on the use of regression 
methods for proportional control of multiple DOFs (Jiang et al 2009; Nielsen et al 2011; Pulliam et al 2011). The same holds true also for all studies presented in this thesis.

\subsection{Sequential versus simultaneous control}

Not only natural movements are continuous, but they also involve simultaneous activation of multiple DOFs. The conventional scheme only allows sequential control of the intended DOF, i.e. only one function can be active at a time. When two DOFs are available, the function selection is accomplished by a muscle cocontraction or by a mechanical switch. Simultaneous control of two DOFs with the direct approach has so far been possible only in patients who underwent TMR (Kuiken et al 2004), given the availability of multiple muscle portions that could be activated independently. The pattern recognition-based strategy also provides

sequential control. The pattern recognition approach per se does not preclude the individuation of the simultaneous activation of two DOFs as a class. However, in practice, the introduction of simultaneous movements would increase the number of classes to be recognized by the classifier, introducing the same problems mentioned above in the matter of proportional control. The simultaneous control of multiple DOFs movements was analyzed by Jiang et al (2009) and Nielsen et al (2011) who estimated wrist joint kinetics from forearm EMG signals in case of simultaneous activation of wrist flexion/extension and radial/ulnar deviation. All studies included in this thesis aim to predict kinematics during proportional and simultaneous activation of the DOFs of the wrist.

\subsection{Normally-limbed subjects versus amputee}

In the literature, several methods can be found that achieve $>90 \%$ classification accuracy in tasks with more than 10 classes (Peerdeman et al 2011). However, most results were obtained in controlled laboratory settings and performance indices would be much lower in clinical settings. In other words, these methods are not 
ready to become available in commercial prostheses. The reasons for such disparity are numerous and some of those are elucidated in the following sections.

A large majority of the research work on myoelectric control relies on normally-limbed individuals rather than subjects with limb deficiencies to evaluate the performance of the proposed novel strategies. Obviously, the importance of this work is unquestionable and experiments in able-bodied individuals are valuable to test the feasibility of new approaches and to provide a basis for future comparison in amputees. However, the validation in amputees is often neglected. Most of the proposed control schemes are built upon the hypothesis that amputees can voluntarily produce different movements of their phantom hand and that these movements are associated with stump muscle activity patterns distinct and reproducible over time (Reilly et al 2006). For this reason, results on individuals with intact limbs reliably translate to the clinical population, at least as relative trend. It has been shown for example in Scheme et al (2011) that the relative performance (measured as classification error) of various classification schemes is consistent between normal and amputee subjects. In any case, traumatic amputation is followed by cortical reorganization (Ramachandran et al 1992; Montoya et al 1998; Lundborg 2000). Muscle shape and volume may also change with disuse (Sanders and Fatone 2011). Moreover, the interface between muscles and electrodes may be different due to the presence of scar tissue (Lake and Dodson 2006). For these reasons, absolute performances are usually lower in amputee than in the normally-limbed population. Therefore, new techniques should always be tested also in the actual target population. Studies II and III of this thesis are devoted to the validation in amputee persons of the estimation of the wrist kinematics from multi-channel EMG according to the strategy proposed in Study I.

\subsection{Electrode shift}

Since the interface between the prosthetic device and the user muscles is based on surface electrodes rather than on chronically implanted sensors, the electrodes happen to be in a slightly different position every time the user dons the prosthesis. This misalignment causes daily variability in the EMG features corresponding to 
a certain movement. Conventional control copes quiet well with this problem. The strength of commercial systems is indeed in their robustness that has determined their widespread use despite the limited functionality. The pattern recognition approach is instead much more sensitive to electrode displacement (Young et al 2011) because based on the assumption that the stump muscle activity associated to a certain movement is consistent over time. This assumption is partially violated also when the subject uses the prosthesis in a different position with respect to that held during the training procedure because muscles can slide beneath the skin with respect to the electrodes when changing the arm position, resulting in an alteration of the recorded EMG pattern (Maclsaac et al 2001). This again causes a degradation of the classification accuracy (Fougner et al 2011). Study III of this thesis investigated the effect of arm position on the prediction of kinematics from EMG in both normally-limbed and amputee subjects. Study IV proposed a method for simultaneous and proportional control of multiple DOFs robust to electrode shift.

\subsection{Training procedure}

The classification accuracy degradation due to electrode shift can be mitigated by training the system at all expected electrode displacements (Hargrove et al 2008) and in multiple limb positions (Fougner at al 2011). The drawback is the lengthening of the duration of the training procedure. For the subject comfort, the training should be as short as possible, especially if envisaged that it needs to be repeated over time, due for example to electrode shift. Jiang et al (2013) proposed a biologically inspired method for online simultaneous and proportional control of two DOFs of the wrist. This approach requires a calibration phase where the user

performs few $(<10)$ repetitions of single DOF movements. The corresponding EMG is used to generate a matrix that translates EMG signals into kinematic variables. The entire procedure takes few minutes and it is even robust to electrode shift (Study IV), so that recalibration is not necessary. The theoretical validation of the aforementioned method has been provided in Study IV. 
In case of conventional control and pattern recognition-based control, the training procedure requires only the recording of EMG signals. Regression methods (Nielsen et al 2011; Studies I-III of this thesis) instead require forces or joint angles to train the system to obtain control signals. Kinetics or kinematics signals can be gathered in unilateral amputees from the hand contralateral to the amputation if they attempt to concurrently perform imaginary movements with the phantom hand and the same real movements with the contralateral hand (mirrored bilateral training). The problem arises in case of bilateral amputees. Although it would be possible to ask the amputee to imitate the movements of a human teacher with his phantom limb (Castellini et al 2009) and to use the teacher kinematics to train the regressor, it would be more difficult to achieve synchrony between the teacher movement and the amputee imitation and this would in turn affect the training of the regressor. Therefore, unsupervised methods for continuous estimation of multiple DOFs are highly desirable. The method proposed in Study IV presents also this important characteristic.

\subsection{Offline versus online training}

The common metric used to validate a new myoelectric control approach based on pattern recognition is the offline classification accuracy (Englehart et al 2003; Hargrove et al 2009; Tenore et al 2009). All pattern recognition-based myoelectric controllers presented in the literature in the last two decades provided classification accuracy around $90 \%$ and new studies that try to improve accuracy further keep appearing. However, accuracy does not necessarily relate to the usability of the system (Kuiken et al 2009). Hargrove et al (2007b) found that in a virtual clothespin placement task, positioning time could be reduced by including the transient portion of contraction signals, even if this resulted in an increase of the classification error. It should not be underestimated that when using a prosthesis, the user is provided with feedback (at least visual) and this can actually contribute to improve the performance. It has for example been shown in Rehbaum et al (2012) that subjects could perform online goal-directed tasks involving simultaneous and proportional control of two degrees of freedom of the wrist although the measured kinematics and the one estimated by 
the control system were only roughly similar. This was likely because the subjects could adaptively compensate for the error produced by the algorithm. Part of the experiments reported in Study IV served to validate the online myoelectric control method proposed by Rehbaum et al (2012).

\subsection{Sensory feedback}

The result of the study from Rehbaum et al (2012) highlights the importance of sensory feedback in myoelectric control. Functional movements results from the integration of motor commands and multimodal sensory feedback (Kandel et al 2000). With the loss of their hand/arm, amputees are also deprived of some sources of sensory feedback, e.g., touch and pressure, and have to rely on vision to ascertain the accomplishment of the intended movement. The continuous recourse to visual feedback increases the cognitive burden of the users and may be uncomfortable for them because they will their movements to appear as natural as possible. The absence of sensory feedback is one important reason of the dissatisfaction in prosthesis users and it is indubitably worth of investigation (Antfolk et al 2013). However, this topic is beyond the scope of this thesis, which focuses on the feed-forward control of a prosthesis. 


\section{AIM OF THE THESIS}

The review of the state-of-the-art showed that the primary requests from upper limb prosthesis users are additional wrist functions, more intuitive control and simultaneous articulation of multiple joints (Atkins et al 1996). The aims of this thesis were:

1) To propose myoelectric control systems for continuous, simultaneous and proportional control of the wrist DOFs during dynamic movements (Studies I-IV);

2) To test the robustness of such systems:

a. with respect to the number of channels used to infer the user intents (Studies I and IV),

b. to variations in limb position (Study III),

c. to electrode shift (Study IV),

d. when applied to amputees with respect to normally-limbed subjects (Studies II-III).

Four studies were conducted to achieve these goals:

\section{Study I: Muceli S and Farina D.}

Simultaneous and proportional estimation of hand kinematics from EMG during mirrored movements at multiple degrees-of-freedom. IEEE Trans Neural Syst Rehabil Eng 20: 3: 371-378, 2012.

\section{Study II: Jiang N, Vest-Nielsen JL, Muceli S and Farina D.}

EMG-based simultaneous and proportional estimation of wrist/hand kinematics in uni-lateral trans-radial amputees. J Neuroeng Rehabil 9: 1: 1-11, 2012.

\section{Study III: Jiang N, Muceli S, Graimann B and Farina D.}


Effect of arm position on the prediction of kinematics from EMG in amputees. Med Biol Eng Comput 1-9, 2012.

\section{Study IV: Muceli S, Jiang N, and Farina D.}

Extracting Signals Robust to Electrode Number and Shift for Online Simultaneous and Proportional Myoelectric Control by Factorization Algorithms. IEEE Trans Neural Syst Rehabil Eng. In press.

The papers are reported at the end of the thesis. Some of the findings reported in this thesis have been presented at the following international conferences:

Muceli S, Jiang N, and Farina D. "Simultaneous and proportional estimation of multiple degrees of freedom in hand kinematics from the surface EMG', XVIIIth Congress of the International Society of Electrophysiology and Kinesiology (ISEK), 16-19 June 2010, Aalborg, Denmark.

Muceli S, Jiang N, and Farina D. "Multichannel Surface EMG Based Estimation of Bilateral Hand Kinematics during Movements at Multiple Degrees of Freedom”, Conf Proc IEEE Engineering in Medicine and Biology Society 1:6066-9, 31 August-4 September 2010, Buenos Aires, Argentina.

Jiang N, Nielsen JLG, Muceli S, and Farina D. "EMG-based Simultaneous and Proportional Estimation of Wrist Kinematics and its Application in Intuitive Myoelectric Control for Unilateral transradial Amputees", BC11 : Computational Neuroscience \& Neurotechnology Bernstein Conference \& Neurex Annual Meeting 2011, 4-6 October 2011, Freiburg, Germany. 


\section{GENERAL DISCUSSION}

This chapter summarizes the main findings of the studies included in this thesis, in particular referring to the limitations of the state-of-the-art control systems, as presented in Chapter 3.

\subsection{Unresolved issues in simultaneous and proportional control of multiple DOFs}

Although the importance of simultaneous myoelectric control of multiple functions was acknowledged since long time (Atkins et al 1996; Englehart et al 2001; Englehart et al 2003; Parker et al 2005; Parker et al 2006), the first attempts to cope with this issue appeared in the literature only recently. Probably the first successful achievement was obtained with TMR patients (Kuiken et al 2004) due to the availability of many independent sources of control. This condition is normally not verified in upper limb amputees. Surface EMG signals recorded from forearm muscles for example are almost inevitably corrupted by crosstalk of nearby muscles. Therefore, to provide simultaneous control of hand/wrist DOFs may become more challenging. Research efforts in this direction are relatively recent (e.g., Jiang et al. 2009; Nielsen et al 2011). The authors proposed force control strategies for simultaneous and proportional articulation of wrist flexion/extension and radial/ulnar deviation based on linear factorization of the EMG signals (Jiang et al 2009) and ANNs (Nielsen et al 2011), respectively. Positive results with the above systems were limited to the two aforementioned DOFs. However, control of the wrist rotation is deemed necessary by amputees (Atkins et al 1996). The failure when trying to control of the third DOF may be due to several reasons: 1) to provide the wrist pronation/supination functions by using signals of the physiologically appropriated muscles is inherently more challenging than the other two DOFs for anatomical reasons; 2) in previous setups, the subject's hand was restrained by the experimental apparatus used to gather force which introduced force translation across the three DOFs; 3) a linear estimator of the force from EMG signals was adopted in Jiang 
et al (2009). Such estimator does not take into account the nonlinearities of the force modulation strategies of the neuromuscular system and surface EMG crosstalk.

\subsection{The myoelectric control system proposed in this thesis}

In this thesis, we proposed myoelectric control systems for continuous (Section 3.2), simultaneous (Section 3.3) and proportional (Section 3.2) control of the complex wrist/hand during dynamic movements. In all studies of this thesis, a position control strategy (Sebelius et al 2006; Pulliam et al 2011) was used rather than a force control approach (Jiang et al 2009; Nielsen et al 2011), in order to circumvent the second limitation of previous approaches listed in Section 5.1. In all studies composing this thesis, the hand was not constrained (Fig. 4), with the aim to provide a training scenario more similar to the one the prosthesis user has to deal with in everyday life. In research settings, training and test data are often collected with the arm resting in a support which eliminates most of the artifacts that are inevitably present in a clinical implementation, i.e., movement artifacts, relative shift between muscles and electrodes which occurs during dynamic contractions. According to the Upper Limb Prosthetic Outcome Measures group, a prosthesis should be tested in the Function, Activity and Participation domains (Hill et al 2009), e.g. in laboratory, in clinic, and in the daily life of the amputee. Most prosthetics research is carried out in the Function domain in a laboratory, and performance degrade when the proposed system are tested in the Activity and Participation domains. We hypothesized that by reducing the mismatch between the training data and the movements that the amputee attempts to perform in real life, this would increase the generalization capability of the algorithm that translates EMG features into the control variable. In other words, we expected that this would reduce the discrepancy between the results obtained in a laboratory and in case of clinical use of the prosthesis by the end user.

In Study I, as well as in Studies II and III, we explored the use of ANNs as translation algorithm because of their ability to learn nonlinear input-output relations (see limitation 3 in Section 5.1). Differently from 
previous studies (Nielsen et al 2011), we used a dedicated ANN for each DOF. Each ANN mapped the EMG amplitude into the joint kinematics corresponding to a certain DOF. The control scheme in Study I comprises also the hand closing because it is a fundamental function provided by all commercial prosthetic devices. Joint kinematics data were recorded with a motion tracking system according to a protocol developed in Study I and used in Studies II and III as well. The processing to convert marker positions into angular displacement was also proposed in Study I and employed in the next two studies. Study I was meant to provide a proof of the feasibility of the control system that will be employed in the thesis. Therefore, it was conducted in normally-limbed individuals to provide a benchmark for future validation in amputees (Study II). To simulate a training strategy applicable with unilateral amputees, kinematics was gathered from the limb contralateral to the one from where EMG was collected while the subject performed mirrored bilateral movements. The same training strategy was employed in Studies II and III.

\subsection{Study I : On the use of high-density EMG}

The challenge in decoding the pronation/supination DOF (limitation 1) is because transradial amputees lost their pronator quadratus muscle and the supinator muscle is deep and therefore not easily accessible with surface electrodes (Section 3.1). In Study I, we investigated the use of high-density EMG recordings (Staudenmann et al 2006) and we hypothesized that it could improve movement decoding especially referring to the wrist rotation and to dynamic tasks in free space. Indeed, the accuracy $\left(\mathrm{r}^{2}\right)$ in the kinematic estimation from the high-density EMG configuration was in the range 79\%-88\% for the four DOFs, proving the feasibility of the approach. More importantly, when employing a reduced configuration with 7 pairs of electrodes equally spaced around the forearm, as in many experimental setups (Castellini et al 2009; Jiang et al 2009; Fougner et al 2011), the estimation of the angular displacement relative to wrist rotation was mainly affected and the estimation of the other three DOFs remained quite accurate. These results indicate that the 


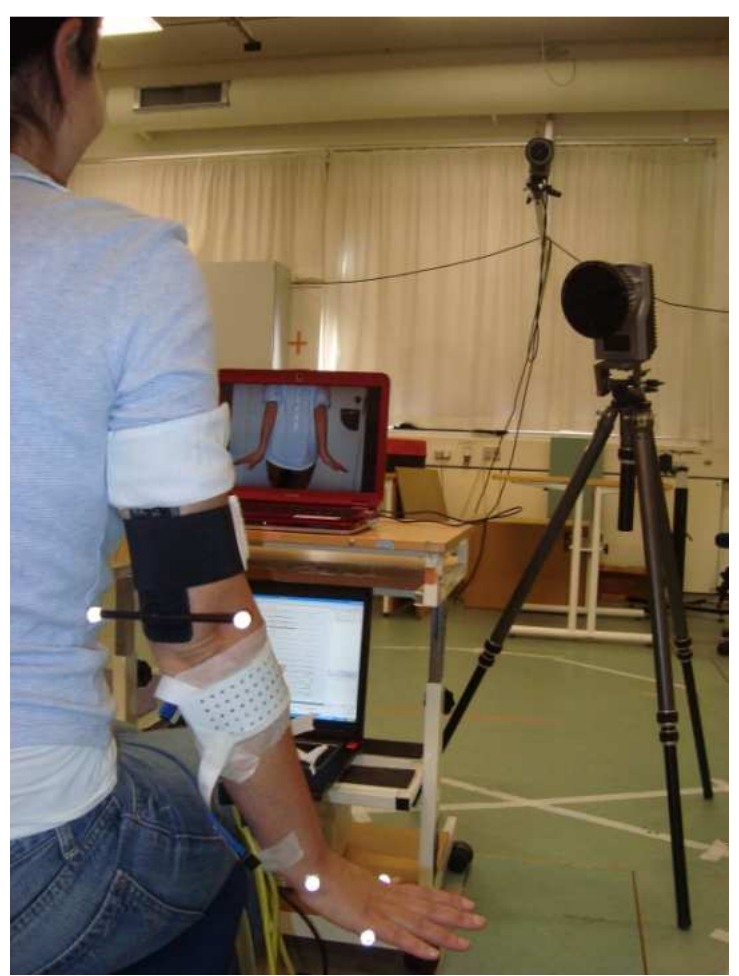

Fig. 4 Experimental setup of Study I. Surface EMG signals were detected from forearm muscles of the right limb and hand kinematics of both limbs was concurrently recorded during the mirrored bilateral movements. The movements to be reproduced were displayed on a computer screen located in front of the subject.

myoelectric control approach proposed in Study I represents a potential solution for simultaneous and proportional control of multiple DOFs in unilateral amputee.

\subsection{Study II : Validation of the proposed myoelectric control strategy in amputees}

Given the results of Study I, it is expected that as long as sufficient muscles remain in the stump of transradial amputees, information embedded in the forearm surface EMG should be sufficient to decode the user intents. Study II presents a systematic investigation on mirror training for estimating kinematics in amputee subjects (Section 3.4). In particular, two groups of amputees were considered with respect to the stump length (long stump and short stump, with stump length approximately $2 / 3$ and $1 / 3$ of the forearm length, respectively). Normally-limbed subjects were also included in the Study. The four DOFs handled in Study I have been reduced to three by excluding the open/close DOF from Study II. Since Study II involved amputees, we wished to reduce the duration of each experimental session because the protocol required them 
to attempt performing combined movements with their phantom limb movements. This might be burdensome for them because they have not been using their amputated side for such complex motor tasks after the amputation. We opted for eliminate from the protocol the open/close DOF because commercial prostheses already provide control of this function. Moreover, the function is served by superficial muscles; therefore, we assume that the performance will be comparable to those obtained in case of flexion/extension which are also controlled by superficial muscles.

Following the result of Study I that performance was reasonable with the reduced configuration, a recording system with 7 bipolar electrodes equally spaced around the forearm was adopted, which is more practical than high-density EMG especially in relation to power consumption and cost of the prosthesis. Nevertheless, in order to compensate for the loss of information due to the inferior number of channels, a set of 4 timedomain features and 6 autoregressive coefficients (Nielsen et al 2011) was extracted from EMG and fed to the ANNs rather than only the amplitude information as in Study I.

The more relevant results pertain to the contralateral scenario: in amputees, EMG was recorded from the stump and kinematics from the intact limb and in control subjects, EMG and kinematics were acquired from two different sides. Amputees with long stump showed similar performance (in terms of accuracy of the kinematic estimation) to the intact limb subjects (at least in the domain) apart from movements where all wrist DOFs were simultaneously involved. The reason for an inferior performance in the latter case was attributed to the fact that the amputees did not use their residual musculature for such complex tasks after the amputation. Performance of the short stump group was obviously inferior to that of able-bodied subjects but also to the performance of amputees with long stump. The most plausible explanation is that the remaining tissue was not sufficient to extract neural control information. Altogether, the results showed that if enough muscle tissue is left after the amputation, the proposed myoelectric control strategy has the potential to be used in clinical settings for unilateral amputees. Further research is warranted to investigate if performance 
improves with practice in order to draw conclusions on the anatomical requirements of the remnant muscles for an acceptable performance of the method.

\subsection{Study III : Effects of variations in limb positions in amputees}

Pattern recognition-based approaches are showed to be affected by variations in limb position with respect to the one held during the collection of the data necessary to train the control system (Fougner et al 2011; Section 3.5). The third study investigated the effect of variations in limb position on the myoelectric control strategies proposed in Study I and refined in Study II.

Investigation was limited to amputees with long stump, since our strategy seems to be effective for that target population (Study II), and to normally-limb persons, for comparison. The control system was the same as in Study II with the only difference that during the collection of the training data, the subjects maintained their arms in three positions (only one position was considered in Study II). When the kinematic estimator was trained with data collected in a certain position and validated with data collected in another position, the accuracy in kinematic estimation was inferior to when training and validation data were collected with the arm in the same position. This finding was common to both groups of subjects.

However, the relative decrease in performance with a change in arm position was smaller for amputees than for the control group in case of movements that involved wrist rotation. Three possible reasons were identified. During surgical amputation, the residual muscles or tendons are anchored by sutures through the bone (myodesis). Therefore, changes in muscle shape and length are likely less considerable in amputees than in able-bodied subjects. Moreover, myoelectric prosthesis users, as in the case of the amputees who participated to the experiments of Study III, likely learned to control their terminal device relying on only forearm muscles, while in general the biceps brachii is also involved in supination. Change in load due to gravity when changing arm position might also be different in the two subject groups because of the limb 
length. In a real use scenario, the amputee would be equipped with a prosthesis, which would lead to similar loading effects when compared to able-bodied users. Therefore, it would be worth investigating if this would affect the performance.

In summary, as previously proposed for pattern recognition approaches, it was confirmed that the drop in performance in case of multi-position use (Fougner et al 2011) might be mitigated collecting training data in multiple positions. However, this modification may make the training cumbersome; therefore, alternative solutions need to be explored.

\subsection{Study IV: Robustness to electrode shift of a control strategy for bilateral}

\section{amputees}

Taken together, the results of Studies I-III show a potential solution that can be applied in unilateral transradial amputees for simultaneous and proportional control of the wrist DOFs. However, some aspects could be improved. First, since the algorithm that translates EMG in kinematics is supervised (ANN), it requires recording of kinematic data. This limits the applicability of the approach to unilateral amputees. For this reason, an unsupervised method would be preferable. This would also simplify the collection of training data in terms of hardware and time duration, which would be beneficial especially if necessary to perform the training with the arm at different positions (Study III).

It is worth noting that all reported findings of Studies I-III were results of offline analysis. Although algorithm performances do not necessary correlates with system usability (Hargrove et al 2007b; Section 3.7), it is possible that such correlation will be stronger for the proposed system because it is intuitive in that it provides simultaneous and proportional control of DOFs by using physiological contractions. Indeed, results may even improve in an online experiment because the subjects can try to improve the performance when they have the opportunity to observe that the movement does not correspond to their intentions. 
Actually, the method proposed by Jiang et al (2009) has recently been tested in an online paradigm where both amputees and intact limb subjects performed a goal-oriented task (Rehbaum et al 2012) and showed better performance than the offline counterpart did. With respect to the original paper, the hand was not restrained, as in Studies I-III, thus the subjects performed dynamic movements. The Jiang's method is based on the assumption that movements are executed by translating low dimensional neural commands (activation signals) into higher dimensional muscle activation patterns through a synergy matrix (muscle synergy model (Tresch et al 1999)). In Jiang et al (2009) and Rehbaum et al (2012), the synergy matrix was extracted by non-negative matrix factorization (Lee and Seung 2001). The use of this algorithm requires that the mixture between activation signals and the synergy matrix is linear instantaneous. However, in general the mixture should be convolutive because signals recorded from the forearm are inevitably affected by crosstalk. Although the method was experimentally tested in both able-bodied and amputee subjects (Rehbaum et al 2012), a theoretical validation of the above assumption was not provided. This was an aim of Study IV. The theoretical validation showed that if the hypothesis is fulfilled, it is possible to extract the activation signals from the EMG signals. In the opposite case, the dimension estimated by linear factorization methods is greater than the number of activation signals.

This issue was addressed in Study IV by factorizing the muscle activation pattern obtained from different configurations with various number of EMG channels $(6,8,16,192)$ recorded during contractions that involve two wrist DOFs: flexion/extension and pronation/supination. The number of investigated DOFs was further reduced to two to maintain the experiment duration reasonable. Flexion/extension and rotation were maintained because, aside from hand open/close, they are the most desired and functionally important missing functions in commercial prostheses for transradial amputees (Atkins et al 1996). It turned out that the dimensionality underlying EMG did not change, supporting the hypothesis of linear instantaneous mixing and, consequently, the use of linear factorization algorithms. Moreover, the activation signals were very similar irrespective of the number of channels considered for the analysis. Since the activation signals are 


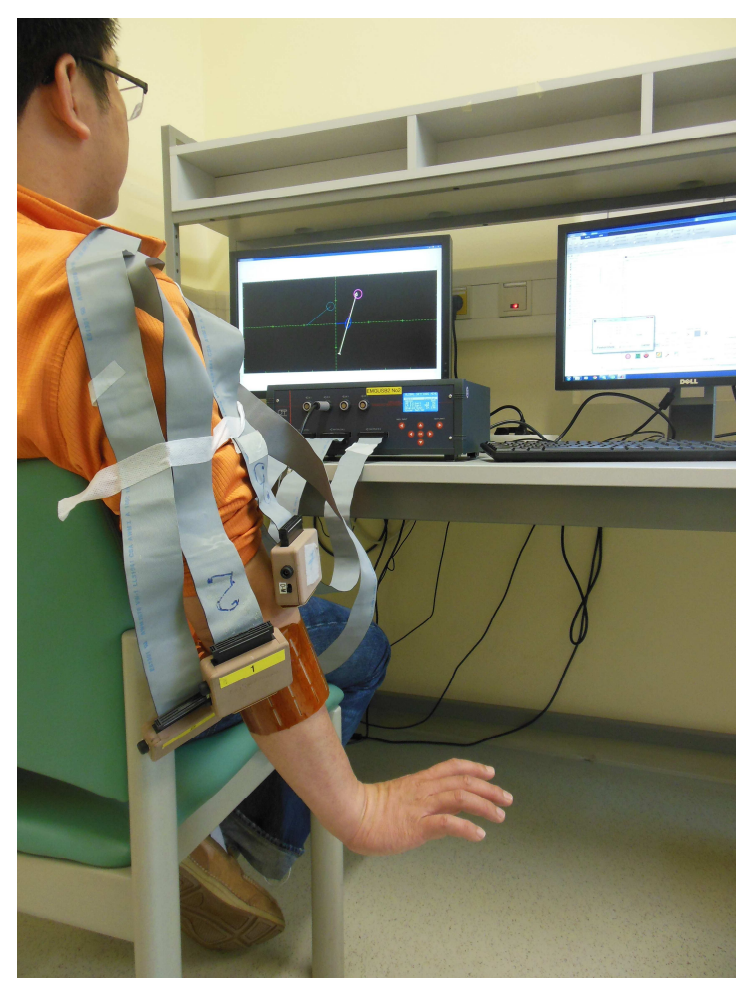

Fig. 5 Experimental setup of Study IV. The subject was instructed to place the tip of the feedback arrow within circular targets that appeared on random locations on the screen. Simultaneous activation of wrist flexion/extension and rotation was necessary to hit the circle.

directly used as control signals, we can conclude that the algorithm employed in Study IV is robust to the number of channels, while the ANN based myoelectric control system was more sensitive to this aspect (Study I). Preliminary investigation also showed that the system presented in Studies I-III is sensitive to electrode shift that may occur in daily use of the prosthesis because it is unlikely that the position of the electrode will be the same each time the user dons the prosthesis. On the other hand, offline analysis revealed that the synergy based method can cope well with the electrode shift if the subject is able to modify slightly the muscle activation, which in turns will result in a change of the activation signals.

Study IV included also an online experiment aimed to validate that the myoelectric control system proposed in Rehbaum et al (2012) is actually robust to electrode number and shift in direction either longitudinal or transversal to the muscle fibers. The experimental setup is represented in Fig. 5. A reference synergy matrix was obtained from a configuration of $\mathrm{N}$ monopolar electrodes each (with $\mathrm{N}=6,8,16$ ), equally spaced 
around the forearm (in two rows in case of $\mathrm{N}=16$ ). For each $\mathrm{N}$, activation signals were calculated by multiplying the pseudo-inverse of the reference synergy matrix and the EMG signals (squared and integrated) obtained from the reference electrode configuration and two configurations obtained by shifting all electrodes of $1 \mathrm{~cm}$ in the two directions while the subjects performed an online goal-oriented task. Generally, shift did not cause any difference in online performances in terms of number of targets reached in the preset time, and the time and path length to reach the target. Similarly, the number of channels did not affect the performance. These properties, in addition to the fact that such factorization is semi-supervised and provides simultaneous control of multiple DOFs, are of relevance for the clinical use of prostheses.

The control strategy validated in Study IV represents therefore a viable solution for bilateral amputees. 


\section{CONCLUSIONS}

This thesis provided strategies for simultaneous and proportional myoelectric control in upper limb amputees. Two strategies were proposed. The first is based on estimating joint kinematics from EMG signals by using ANNs while the subject performs dynamic movements in free space. The method has been tested in amputees and it provided an accurate estimation even in case of multiple positions of the arm, if taken into account during training. The tests were limited to offline analysis but it is expected that the system would provide similar performance in daily life activities because the training scenario was designed in order to include the problems a prosthesis user has to deal with in daily use of the prosthesis (as changes in muscle length, shape and load during multi-position use). Indeed, it is expected that results will even improve in case of online control because the subject will be able to exploit visual feedback and correct errors by altering the muscle activation level. The method is intuitive in that it provides simultaneous and proportional control of multiple functions by using physiologically appropriated muscle contractions. The main limitation of the

proposed approach resides in its supervised nature. Kinematic data that could be easily acquired in unilateral amputees, for example by using an instrumented glove, but the limitation remains in case of bilateral amputees.

The better performance obtained with the system proposed in this thesis with respect with the method based on linear factorization (Jiang et al 2009) may be due to three reasons: 1) the fact that the hand was not restrained during the collection of training data;2) the recourse to a non-linear mapping between EMG and the control variable (position); 3) the addition of combined movements in the data set used to train the system. In the thesis, we did not investigate which problem was more detrimental for the Jiang's control system. We recognized those as potential problems in the previous work and we tried to address all of them at once. 
However, an online implementation of the method based on linear factorization (Rehbaum et al 2012) provided successful results in both able-bodied and amputee subjects, suggesting that the last two reasons do not have significant influence, at least during online use of the control system. The results of Study IV actually showed that the surface EMG acquired at the forearm can be considered a linear instantaneous mixture of activation signals. Therefore, the use of linear factorization algorithms is justified. The method used in Study IV is intuitive, unsupervised, and robust to electrode number and shift. The system has been already tested in amputees during an online target control. These properties are all relevant for the clinical use of prostheses.

In conclusion, the thesis validated two myoelectric control systems for simultaneous and proportion activation of the complex wrist/hand in unilateral and bilateral amputees. 


\section{REFERENCES}

Ajiboye AB and Weir RF. A heuristic fuzzy logic approach to EMG pattern recognition for multifunctional prosthesis control. IEEE Trans Neural Syst Rehabil Eng 13: 3: 280-291, 2005.

Antfolk C, D'Alonzo M, Rosén B, Lundborg G, Sebelius F and Cipriani C. Sensory feedback in upper limb prosthetics. Expert Rev Med Devices 10: 1: 45-54, 2013.

Atkins DJ, Heard DC and Donovan WH. Epidemiologic overview of individuals with upper-limb loss and their reported research priorities. J Prosthet Orthot 8: 1: 2-11, 1996.

Biddiss EA and Chau TT. Upper limb prosthesis use and abandonment: A survey of the last 25 years. Prosthet Orthot Int 31: 3: 236-257, 2007.

Boschmann A, Platzner M, Robrecht M, Hahn M and Winkler M. Development Of A Pattern Recognition-Based Myoelectric Transhumeral Prosthesis With Multifunctional Simultaneous Control Using A Model-Driven Approach For Mechatronic Systems. Proceedings of the 2011 MyoElectric Controls/Powered Prosthetics Symposium Fredericton, New Brunswick, Canada: August 14-19, 2011.

Butterfaß J, Grebenstein M, Liu H and Hirzinger G. DLR-Hand II: Next generation of a dextrous robot hand. Proceedings 2001 ICRA. IEEE International Conference on Robotics and Automation, 2001, 1: 109$114,2001$.

Carrozza M, Cappiello G, Micera S, Edin BB, Beccai L and Cipriani C. Design of a cybernetic hand for perception and action. Biol Cybern 95: 6: 629-644, 2006. 
Carrozza M, Massa B, Micera S, Lazzarini R, Zecca M and Dario P. The development of a novel prosthetic hand-ongoing research and preliminary results. IEEE/ASME Trans Mechatron 7: 2: 108-114, 2002.

Castellini C, Gruppioni E, Davalli A and Sandini G. Fine detection of grasp force and posture by amputees via surface electromyography. J Physiol Paris 103: 3: 255, 2009.

Chan FH, Yang Y, Lam F, Zhang Y and Parker PA. Fuzzy EMG classification for prosthesis control. IEEE Trans Rehab Eng 8: 3: 305-311, 2000.

Childress DS. Historical aspects of powered limb prostheses. Clin Prosthet Orthot 9: 1: 2-13, 1985.

Chu J, Moon I, Lee Y, Kim S and Mun M. A supervised feature-projection-based real-time EMG pattern recognition for multifunction myoelectric hand control. IEEE/ASME Trans Mechatronics 12: 3: 282-290, 2007.

Cipriani C, Controzzi M and Carrozza MC. The SmartHand transradial prosthesis. J Neuroeng Rehabil 8: 1: 29, 2011

Dhillon GS, Lawrence SM, Hutchinson DT and Horch KW. Residual function in peripheral nerve stumps of amputees: implications for neural control of artificial limbs. J Hand Surg 29: 4: 605-615, 2004.

Dillingham TR, Pezzin LE and MacKenzie EJ. Incidence, acute care length of stay, and discharge to rehabilitation of traumatic amputee patients: an epidemiologic study. Arch Phys Med Rehabil 79: 3: 279-287, 1998.

Dorcas D and Scott R. A three-state myo-electric control. Med Biol Eng Comput 4: 4: 367-370, 1966.

Doubler JA and Childress DS. An analysis of extended physiological proprioception as a prosthesis-control technique. J Rehabil Res Dev 21: 1: 5-18, 1984. 
Englehart K, Hudgin B and Parker PA. A wavelet-based continuous classification scheme for multifunction myoelectric control. IEEE Trans Biomed Eng 48: 3: 302-311, 2001.

Englehart K and Hudgins B. A robust, real-time control scheme for multifunction myoelectric control. IEEE Trans Biomed Eng 50: 7: 848-854, 2003.

Englehart K, Hudgins B and Parker P. Multifunction control of prostheses using the myoelectric signal. In: Teodorescu HNL and Jain LC. Intelligent Systems and Technologies in Rehabilitation Engineering. Boca Raton: CRC Press LLC. 153-208, 2001.

Englehart K, Hudgins B, Parker PA and Stevenson M. Classification of the myoelectric signal using time-frequency based representations. Med Eng Phys 21: 6: 431-438, 1999.

Farina D, Merletti R and Enoka RM. The extraction of neural strategies from the surface EMG. $J$ Appl Physiol 96: 4: 1486-1495, 2004.

Farina D, Yoshida K, Stieglitz T and Koch KP. Multichannel thin-film electrode for intramuscular electromyographic recordings. J Appl Physiol 104: 3: 821-827, 2008.

Farry K, Fernandez J, Abramczyk R, Novy M and Atkins D. Applying genetic programming to control of an artificial arm. Proceedings of the 2007 MyoElectric Controls/Powered Prosthetics Symposium Fredericton, New Brunswick, Canada, 1997.

Fougner A, Scheme E, Chan AD, Englehart K and Stavdahl Ø. Resolving the limb position effect in myoelectric pattern recognition. IEEE Trans Neural Syst Rehabil Eng 19: 6: 644-651, 2011. 
Fougner A, Stavdahl O, Kyberd P, Losier Y and Parker P. Control of Upper Limb Prostheses: Terminology and Proportional Myoelectric Control-A Review. IEEE Trans Neural Syst Rehabil Eng 20: 5: 663-677, 2012.

Fuglevand AJ, Winter DA and Patla AE. Models of recruitment and rate coding organization in motor-unit pools. J Neurophysiol 70: 6: 2470-2488, 1993.

Gilroy AM, MacPherson BR and Ross LM. Atlas of anatomy. Thieme Medical Pub, 2008.

Graimann B and Dietl H. Introduction to Upper Limb Prosthetics. In: Farina D, Jensen W, Akay M. Introduction to Neural Engineering for Motor Rehabilitation. Wiley-IEEE Press, 2013.

Graupe D and Cline WK. Functional separation of EMG signals via ARMA identification methods for prosthesis control purposes. IEEE Trans Syst, Man, Cybern 2: 252-259, 1975.

Hargrove LJ, Englehart K and Hudgins B. A comparison of surface and intramuscular myoelectric signal classification. IEEE Trans Biomed Eng 54: 5: 847-853, 2007a.

Hargrove LJ, Li G, Englehart KB and Hudgins BS. Principal components analysis preprocessing for improved classification accuracies in pattern-recognition-based myoelectric control. IEEE Trans Biomed Eng 56: 5: 1407-1414, 2009.

Hargrove L, Englehart $\mathbf{K}$ and Hudgins B. A training strategy to reduce classification degradation due to electrode displacements in pattern recognition based myoelectric control. Biomed Signal Process Contr 3: 2 : $175-180,2008$.

Hargrove L, Losier Y, Lock B, Englehart K and Hudgins B. A real-time pattern recognition based myoelectric control usability study implemented in a virtual environment. Proceedings of the 2007 Annual 
International Conference of the IEEE Engineering in Medicine and Biology Society (EMBC), Lyon, France. 4842-4845, $2007 b$.

Herberts P and Petersen I. Possibilities for control of powered devices by myoelectric signals. Scand J Rehabil Med 2: 4: 164-170, 1970.

Hill W, Stavdahl Ø, Hermansson LN, Kyberd P, Swanson S and Hubbard S. Functional outcomes in the WHO-ICF model: establishment of the Upper Limb Prosthetic Outcome Measures Group. Journal of prosthetics and orthotics 21: 2: 115-119, 2009.

Huang H, Zhou P, Li G and Kuiken TA. An analysis of EMG electrode configuration for targeted muscle reinnervation based neural machine interface. IEEE Trans Neural Syst Rehabil Eng 16: 1: 37-45, 2008.

Hudgins B, Parker $\mathbf{P}$ and Scott RN. A new strategy for multifunction myoelectric control. IEEE Trans Biomed Eng 40: 1: 82-94, 1993.

Jiang N, Dosen S, Müller K and Farina D. Myoelectric control of artificial limbs: is there the need for a change of focus? IEEE Signal Process Mag 29: 5: 149-152, 2012.

Jiang N, Englehart KB and Parker PA. Extracting simultaneous and proportional neural control information for multiple-DOF prostheses from the surface electromyographic signal. IEEE Trans Biomed Eng 56: 4: 1070-1080, 2009.

Kamavuako EN, Farina D, Yoshida K and Jensen W. Relationship between grasping force and features of single-channel intramuscular EMG signals. J Neurosci Methods 185: 1: 143-150, 2009.

Kandel ER, Schwartz JH and Jessell TM. Principles of neural science. McGraw-Hill New York, 2000. 
Kelly MF, Parker PA and Scott RN. The application of neural networks to myoelectric signal analysis: a preliminary study. IEEE Trans Biomed Eng 37: 3: 221-230, 1990.

Kelly MF, Parker PA and Scott RN. Myoelectric signal analysis using neural networks. IEEE Eng Med Biol Mag 9: 1: 61-64, 1990.

Kobrinski A, Bolkovitin S and Voskoboinikova L. Problems of bioelectric control. Automatic and Remote Control, Proc.1stIFAC Int.Cong 2: 619, 1960.

Kuiken T, Dumanian G, Lipschutz R, Miller L and Stubblefield K. The use of targeted muscle reinnervation for improved myoelectric prosthesis control in a bilateral shoulder disarticulation amputee. Prosthet Orthot Int 28: 3: 245-253, 2004.

Kuiken TA, Li G, Lock BA, Lipschutz RD, Miller LA, Stubblefield KA and Englehart KB. Targeted muscle reinnervation for real-time myoelectric control of multifunction artificial arms. JAMA 301: 6: 619$628,2009$.

Lake C and Dodson R. Progressive upper limb prosthetics. Phys Med Rehabil Clin N Am 17: 1: 49, 2006.

Lee $\mathbf{L}$ and Seung D. Algorithms for non-negative matrix factorization. Adv Neural Inf Process Syst 13: 556562,2001

Lucas M, Gaufriau A, Pascual S, Doncarli C and Farina D. Multi-channel surface EMG classification using support vector machines and signal-based wavelet optimization. Biomed Signal Process Contr 3: 2: 169-174, 2008.

Lundborg G. Brain plasticity and hand surgery: an overview. J Hand Surg Br 25: 3: 242-252, 2000. 
Maclsaac D, Parker P, Scott R, Englehart K and Duffley C. Influences of dynamic factors on myoelectric parameters. IEEE Eng Med Biol Mag 20: 6: 82-89, 2001.

McKeever FM. Upper-extremity amputations and prostheses. J Bone Joint Surg Am 26: 4: 660-706, 1944.

Merletti R, Botter A, Troiano A, Merlo E and Minetto MA. Technology and instrumentation for detection and conditioning of the surface electromyographic signal: state of the art. Clin Biomech (Bristol, Avon) 24: 2 : $122-134,2009$.

Micera S, Carpaneto J and Raspopovic S. Control of hand prostheses using peripheral information. IEEE Rev Biomed Eng 3: 48-68, 2010.

Micera S, Sabatini AM and Dario P. On automatic identification of upper-limb movements using smallsized training sets of EMG signals. Med Eng Phys 22: 8: 527-533, 2000.

Momen K, Krishnan S and Chau T. Real-time classification of forearm electromyographic signals corresponding to user-selected intentional movements for multifunction prosthesis control. IEEE Trans Neural Syst Rehabil Eng 15: 4: 535-542, 2007.

\section{Montoya P, Ritter K, Huse E, Larbig W, Braun C, Töpfner S, Lutzenberger W, Grodd W, Flor H and}

Birbaumer N. The cortical somatotopic map and phantom phenomena in subjects with congenital limb atrophy and traumatic amputees with phantom limb pain. Eur J Neurosci 10: 3: 1095-1102, 1998.

Nielsen JLG, Holmgaard S, Jiang N, Englehart KB, Farina D and Parker PA. Simultaneous and proportional force estimation for multifunction myoelectric prostheses using mirrored bilateral training. IEEE Trans Biomed Eng 58: 3: 681-688, 2011. 
Park S and Lee S. EMG pattern recognition based on artificial intelligence techniques. IEEE Trans Rehab Eng 6: 4: 400-405, 1998.

Parker P, Englehart K and Hudgins B. Myoelectric signal processing for control of powered limb prostheses. J Electromyogr Kinesiol 16: 6: 541, 2006.

Parker P, Englehart K and Hudgins B. Control of powered upper limb prostheses. In: Merletti R and Parker P. Physiology, engineering, and noninvasive applications. Electromyography 453-475, 2005.

Peerdeman B, Boere D, Witteveen H, Hermens H, Stramigioli S, Rietman J, Veltink P and Misra S. Myoelectric forearm prostheses: State of the art from a user-centered perspective. J Rehabil Res Dev 48: 6: 719-738, 2011.

Penfield W and Boldrey E. Somatic motor and sensory representation in the cerebral cortex of man as studied by electrical stimulation. Brain 1937.

Pons J, Rocon E, Ceres R, Reynaerts D, Saro B, Levin S and Van Moorleghem W. The MANUS-HAND dextrous robotics upper limb prosthesis: mechanical and manipulation aspects. Autonomous Robots 16: 2: 143-163, 2004.

Popović D and Sinkjaer T. Control of movement for the physically disabled: control for rehabilitation technology. Springer Verlag, 2000.

Pulliam CL, Lambrecht JM and Kirsch RF. EMG-Based Neural Network Control of Transhumeral Prostheses. J Rehabil Res Dev 48: 6: 739, 2011.

Raichle KA, Hanley MA, Molton I, Kadel NJ, Campbell K, Phelps E, Ehde D and Smith DG. Prosthesis use in persons with lower-and upper-limb amputation. J Rehabil Res Dev 45: 7: 961, 2008. 
Rakic M. The Belgrade hand prosthesis. Proc. Instn. Mech. Engrs183: 1968-1969, 1969.

Ramachandran V, Stewart M and Rogers-Ramachandran D. Perceptual correlates of massive cortical reorganization. Neuroreport 3: 7: 583-586, 1992.

Rehbaum H, Jiang N, Paredes L, Amsuess S, Graimann B and Farina D. Real Time Simultaneous and Proportional Control of Multiple Degrees of Freedom from surface EMG: preliminary results on subjects with limb deficiency. Proceedings of the 2012 Annual International Conference of the IEEE Engineering in Medicine and Biology Society (EMBC), San Diego, USA, 1346-1349, 2012.

Reilly KT, Mercier C, Schieber MH and Sirigu A. Persistent hand motor commands in the amputees' brain. Brain 129: 8: 2211-2223, 2006.

Reiter R. Eine neue Electrokunsthand. Grenzgebiete der Medizin 4: 133, 1948.

Sanders JE and Fatone S. Residual limb volume change: Systematic review of measurement and management. J Rehabil Res Dev 48: 8: 949-986, 2011.

Saridis GN and Gootee TP. EMG pattern analysis and classification for a prosthetic arm. IEEE Trans Biomed Eng 6: 403-412, 1982.

Scheme EJ, Englehart KB and Hudgins BS. Selective classification for improved robustness of myoelectric control under nonideal conditions. IEEE Trans Biomed Eng 58: 6: 1698-1705, 2011.

Schultz AE and Kuiken TA. Neural interfaces for control of upper limb prostheses: the state of the art and future possibilities. PM R. 3: 1: 55-67, 2011.

Scott R and Parker P. Myoelectric prostheses: State of the art. J Med Eng Technol 12: 4: 143-151, 1988. 
Sebelius F, Eriksson L, Balkenius C and Laurell T. Myoelectric control of a computer animated hand: A new concept based on the combined use of a tree-structured artificial neural network and a data glove. $J$ Med Eng Technol 30: 1: 2-10, 2006.

Sensinger JW, Lock BA and Kuiken TA. Adaptive pattern recognition of myoelectric signals: exploration of conceptual framework and practical algorithms. IEEE Trans Neural Syst Rehab Eng 17: 3: 270-278, 2009.

Shenoy P, Miller KJ, Crawford B and Rao RP. Online electromyographic control of a robotic prosthesis. IEEE Trans Biomed Eng 55: 3: 1128-1135, 2008.

Silcox DH,3rd, Rooks MD, Vogel RR and Fleming LL. Myoelectric prostheses. A long-term follow-up and a study of the use of alternate prostheses. J Bone Joint Surg Am 75: 12: 1781-1789, 1993.

Simpson D. The choice of control system for the multimovement prosthesis: extended physiological proprioception (epp). In: Herberts P.The Control of Upper-Extremity Prostheses and Orthoses. Thomas; Springfield, IL146-150, 1974.

Staudenmann D, Kingma I, Daffertshofer A, Stegeman DF and van Dieën JH. Improving EMG-based muscle force estimation by using a high-density EMG grid and principal component analysis. IEEE Trans Biomed Eng 53: 4: 712-719, 2006.

Tenore FV, Ramos A, Fahmy A, Acharya S, Etienne-Cummings R and Thakor NV. Decoding of individuated finger movements using surface electromyography. IEEE Trans Biomed Eng 56: 5: 1427-1434, 2009.

Tresch MC, Saltiel P and Bizzi E. The construction of movement by the spinal cord. Nat Neurosci 2: 2: $162-167,1999$. 
Wang G, Yan Z, Hu X, Xie H and Wang Z. Classification of surface EMG signals using harmonic wavelet packet transform. Physiol Meas 27: 12: 1255, 2006.

Weir Rf, Troyk PR, DeMichele GA, Kerns D, Schorsch JF and Maas H. Implantable myoelectric sensors (IMESs) for intramuscular electromyogram recording. IEEE Trans Biomed Eng 56: 1: 159-171, 2009.

Wirta RW, Taylor DR and Finley FR. Pattern recognition arm prosthesis: A historical perspective-a final report. Bull Prosthet Res 10: 30: 8-35, 1978.

Wright TW, Hagen AD and Wood MB. Prosthetic usage in major upper extremity amputations. $J$ Hand Surg 20: 4: 619, 1995.

Yoshida K, Farina D, Akay M and Jensen W. Multichannel intraneural and intramuscular techniques for multiunit recording and use in active prostheses. Proc IEEE 98: 3: 432-449, 2010.

Young AJ, Hargrove LJ and Kuiken TA. The effects of electrode size and orientation on the sensitivity of myoelectric pattern recognition systems to electrode shift. IEEE Trans Biomed Eng 58: 9: 2537-2544, 2011.

Zardoshti-Kermani M, Wheeler BC, Badie K and Hashemi RM. EMG feature evaluation for movement control of upper extremity prostheses. IEEE Trans Rehab Eng 3: 4: 324-333, 1995.

Zecca M, Micera S, Carrozza M and Dario P. Control of multifunctional prosthetic hands by processing the electromyographic signal. Crit Rev Biomed Eng 30: 4-6: 459, 2002.

Zhou P, Lowery MM, Englehart KB, Huang H, Li G, Hargrove L, Dewald JP and Kuiken TA. Decoding a new neural-machine interface for control of artificial limbs. J Neurophysiol 98: 5: 2974-2982, 2007. 